that he has an incentive to check and control running costs. The disadvantages are that he pays slightly more per unit consumed, and the supply is apt to be interrupted at inconvenient times. To the supply company, the advantages are that there is less accounting as there are no bills, there is a reduction in bad debts, and special applications can be used in hotels and boarding houses. On the other hand, the reading and collecting cost is increased and so also is the maintenance. Mention of coin mechanisms in connexion with measuring holy water beg $\mathrm{n}$ about A.D. 200. A history and criticism of various types of 'coin mechanisms' in connexion with electric meters are given in a paper by J. Prince and M. Whitehead read to the Institution of Electrical Engineers on April 2. Most of the difficulties in connexion with these meters, including the prevention of fraudulently tampering with them, have now been overcome. One of the outstanding points which affect the use of coin mechanisms is the psychological reaction of the peoples concerned. According to the authors, there is a definite objection to prepayment in both Canada and the United States. They are not used in Denmark, France and Portugal. A few are in use in Holland, Austria, Switzerland, New Zealand and Italy. Great Britain seems to be the only country in which there is a great demand for prepayment meters; probably because it provides the best means of promoting the use of electricity among people of small means.

\section{Journal of the University of Manchester}

From the University of Manchester we have received a copy of the University's Journal, No. 1, vol. 1, published by the Manchester University Press. In an inaugural message from the chairman of Council, Sir Christopher Needham, the Journal is described as a new venture designed by the Council to meet what it feels to be a responsibility in regard to graduates, to provide news of University interest and information of developments in University policy as well as personal matters. Conversely, an article by Mr. David Cardwell, chairman of Convocation, reminds graduates that active membership of Convocation (which has, since 1915, followed automatically on graduation) affords a means of service whereby the life-long debt they owe to their University may, in some measure, be repaid. The realization of this ideal has been facilitated by the formation of Groups of Convocation formed in Manchester, London, Leeds and Sheffield and contemplated at Oxford, for discussing matters of University interest and such social and other activities as their members may desire. Sir Ernest Simon contributes an article, "A Time for Expansion: the New Buildings and the Future", describing buildings just completed at a cost of $£ 100,000$, others (including a new dental school and hospital and physical chemical research laboratory, swimming bath, etc.) which it is hoped to complete by the end of 1938, and a project, illustrated by an architect's drawing, for further urgently needed developments destined to form with the buildings already mentioned a dignified and impressive quadrangle. Among other contributors to the journal are: Prof. A. H. Gibson (on the Department of Engineering), Prof. Edward Fiddes (on "Some Teachers of Owens College"), Dr. Tyson (on "The Library and its Uses") and Prof. G. H. Thompson (his Ludwig Mond lecture on "Intelligence and Civilisation"). Copies of the Journal will be supplied without charge and on application, to graduates and friends of the University.

\section{Dr. H. L. Richardson}

Dr. H. L. Richardson, of the Chemistry Department, Rothamsted Experimental Station, has been appointed adviser in soils and fertilizers to the National Agricultural Research Bureau, Shaolingwei, Nanking, China. This institution, which was founded in 1931, possesses extensive laboratories and a farm of 400 acres, and has already made great progress in the investigation of crop production, plant diseases, animal production, and crop recording. In addition to conducting experiments at Nanking, it works in close collaboration with the numerous provincial research stations in China. Dr. Richardson received his training at Victoria University College, New Zealand, and the University of London, and joined the Rothamsted staff in 1927. He has been particularly associated with the developments in soils and fertilizers.

\section{Indian Institute of Science}

IT is reported from Bangalore that, at a meeting of the Governing Council of the Indian Institute of Science held on June 1, Sir C. V. Raman decided to sever his connexion with the Institute. The Council proposed that he should continue in the Institute as professor of physics without administrative powers, and suggested the appointment of an interim director to administer the affairs of the Institute pending the appointment of a new director. Sir C. V. Raman declined the offer of the Council and was unwilling to continue as a subordinate to any other director. It was recommended by the Irvine Committee that a registrar should be appointed to relieve the director of administrative duties and to be directly responsible to the Governing Council. Early this year, it was reported that $\mathrm{Mr}$. R. H. Beckett had been appointed registrar of the Institute, but we understand that, though he was offered the post, he did not accept it. We are now informed that the registrar will be Mr. C. E. W. Jones, C.I.E., lately director of public instruction, Central Provinces.

\section{Chemical Engineering Exhibition in Germany}

Announcements have been issued of the meeting in Frankfort-on-Main during the week July 2-11 of the various bodies in Germany concerned with chemical engineering and the holding at the same time of the Eighth Chemical Engineering Exhibition, widely known as the "Achema". At the last Achema Exhibition, held in Cologne in 1934, an impressive picture was given of the high standard of production of chemical engineering plant and apparatus in Germany and the exhibition attracted 49,000 visitors. 
In the interim, the importance of this branch of industry has increased all over the world and in addition there has been an unprecedented industrial development in Germany brought about by the planned transformation of the national economic system. It is expected, therefore, that the Exhibition next July will offer unusual opportunities and that it will attract a large number of expert visitors from all parts. The Achema Bureau is located in Berlin, W.35, Potsdamerstrasse 103a.

\section{Proton-Neutron Exchange Interaction}

REFERring to his letter in Nature of June 12 (p. 1021), Mr. H. J. Bhabha states that he omitted to insert the following at the beginning of the final paragraph : "The above experiment may be done with cosmic rays, but it must be emphasized that we do not know that the penetratmg group consists of protons, even though we know it cannot consist of electrons obeying the theory."

\section{The Night Sky in July}

THE duration of darkness is too short this month to scan a number of interesting objects. Mars, Jupiter and Saturn are to be seen, followed by Venus, which is a bright morning star. On July 17 at $21^{\mathrm{h}}$ U.T. $\left(=22^{\mathrm{h}}\right.$ summer time), Mars is in conjunction with the moon, and an occultation is visible from Great Britain. The disappearance of Mars behind the moon as seen from Greenwich takes place at $21^{\mathrm{h}} 17 \cdot 7^{\mathrm{m}}$ and the reappearance at $22^{\mathrm{h}} 19 \cdot 8^{\mathrm{m}}$. Jupiter is in opposition on July 15 ; its equatorial diameter is $47 \frac{1}{2}$ " and its polar diameter $3^{\prime \prime}$ less, the oblateness of the disk being apparent in quite a small telescope. On July $22^{\mathrm{d}} 21^{\mathrm{h}}$, Jupiter is in conjunction with the moon. The configurations of the four inner satellites of the planet are given for $23^{\mathrm{h}} 45^{\mathrm{m}}$ in the Nautical Almanac of 1937, p. 625. Saturn with its ring system is, of course, nearly always an attractive object for observation with a refractor of 3 inches aperture or larger. The planet is stationary amongst the stars on July 18. The moon is new on July 8 at $4 \cdot 2^{\mathrm{h}}$ and full on July 23 at $12 \cdot 8^{\mathrm{h}}$. The occultation with Mars when the moon is $9 \cdot 7^{\mathrm{d}}$ old has been mentioned above. On July 31 a conjunction of Mercury with the bright star Regulus may be noted. The planet is only $0 \cdot 4^{\circ}$ north of the star (geocentric positions). About midnight ( $23^{\mathrm{h}}$ U.T.) in the middle of the month, a bright and interesting stretch of the Milky Way is passing the meridian of London. The Constellations Scorpio, Sagittarius, Aquila, Cygnus (south of the zenith) and Cassiopeia, Perseus and Auriga (to the north) mark its span. In latitudes somewhat farther south than that of London, the galactic star clouds in Scorpio and Sagittarius are an unforgettable sight which may be guessed at on clear moonless nights in Great Britain. Though less spectacular, the low eastern sky at midnight contains the constellation Andromeda, and by locating the great nebula, which can be done with the unaided eye, we are seeing out to the depths of space beyond our galactic system. A number of meteor radiants are active during July, among which may be noted the $\alpha \beta$ Perseids with radiant at R.A. $3^{\mathrm{h}} 12^{\mathrm{m}}$ : Dec. $43^{\circ} \mathrm{N}$.; $\gamma$ Draconids (radiant, R.A. $17^{\mathrm{h}} 56^{\mathrm{m}}:$ Dec. $48^{\circ}$ N.) and the $\delta$ Aquarids (radiant R.A. $22^{\mathrm{h}} 36^{\mathrm{m}}$ : Dec. $\left.11^{\circ} \mathrm{S}.\right)$. Some swift meteors may be seen from the radiant at R.A. $21^{\mathrm{h}} 0^{\mathrm{m}}$; Dec. $48^{\circ} \mathrm{N}$.- the $\alpha$ Cygnids.

\section{Announcements}

H.M. THE KING has nominated Sir Arthur MacNalty to be for five years a member of the General Council of Medical Education in the United Kingdom in succession to Sir Henry Dale.

THE following awards from the Lady Tata Memorial Fund for research in blood diseases, with special reference to leukæmia, have recently been made: Grants for research expenses, Dr. Julius EngelbrethHolm (Copenhagen), Prof. Karl Jarmai (Budapest), Prof. James MeIntosh (London), Prof. Charles Oberling (Paris), Prof. Eugene Opie and Dr. Jacob Furth (New York), Dr. Georg Weitzmann (Leipzig) and Dr. Lucy Wills (London); Scholarships, Dr. Jørgen Bichel (Aarhus, Denmark) and Dr. Edoardo Storti (Pavia, Italy).

A Conference on the "Challenge to Democracy" will be held at Ashridge College, Berkhamsted, by the Association for Education in Citizenship, on July 8-14. Further information can be obtained from the Secretary, Association for Education in Citizenship, 10 Victoria Street, S.W.1.

As earthquake of moderate intensity was recorded at Kew Observatory on June 21. The first impulses were registered at $15 \mathrm{hr} .26 \mathrm{~min} .2 \mathrm{sec}$. G.M.T. The records indicate that the shock was located about 6,000 miles away, probably in Peru.

Prof. Hugo Spatz has been appointed director of the Kaiser Wilhelm Institute for Cerebral Investigations.

AN international congress of public health consisting of ten sections will be held in Paris on July 1-10. Further information can be obtained from the Secrétariat Général, Laboratorie d'Hygiene, Faculte de Médecine, rue de l'Ecole de Médecine, Paris, $5^{\mathrm{e}}$

The Belgian Government has decided to organize a campaign of health with the trtle of the National Crusade of Health under the direction of the Red Cross.

Dr. Max Wien, professor of physics at Jena, and Prof Oskar Seyffert at Dresden, have been awarded the Goethe Medal for art and science by the German Chancellor.

THE first World Congress on the Voice, organized by Euphonia, will be held at La Maison de la Chimie, Paris, on September 19-28. Further information can be obtained from Dr. Wicart, 92 Avenue de Wagram, Paris. 